https://helda.helsinki.fi

\title{
Watershed management benefits in a hypothetical, real intention and real willingness to pay approach
}

\section{Lehtoranta, Virpi}

2017-10

Lehtoranta , V , Kosenius , A-K \& Seppälä , E 2017 , ' Watershed management benefits in a hypothetical, real intention and real willingness to pay approach ' , Water Resources Management, vol. 31 , no. 13 , pp. 4117-4132 . https://doi.org/10.1007/s11269-017-1733-3

http://hdl.handle.net/10138/309073

https://doi.org/10.1007/s11269-017-1733-3

unspecified

acceptedVersion

Downloaded from Helda, University of Helsinki institutional repository.

This is an electronic reprint of the original article.

This reprint may differ from the original in pagination and typographic detail.

Please cite the original version. 
1 The accepted manuscript for Water Resources and Management (WARM-D-16-01447)

2 Watershed management benefits in a hypothetical, real intention and real willingness to

3 pay approach

4

5 Lehtoranta, Virpi ${ }^{a *}$, Kosenius, Anna-Kaisa ${ }^{\mathrm{b}}$, Seppälä, Elina ${ }^{\mathrm{a} 1}$,

6

$7 \quad{ }^{a}$ Finnish Environment Institute (SYKE), P.O. Box 140, FI-00251 Helsinki, Finland,

$8 \quad$ firstname.surname@ymparisto.fi, tel. +358 295251 361, fax. +358 954902590

$9 \quad{ }^{b}$ Department of Economics and Management, University of Helsinki, P.O. Box 27

10 (Latokartanonkaari 9), FI-00014 University of Helsinki, Finland

$11{ }^{1}$ Present address: Northern Satakunta municipal federation for basic services and public

12 utilities (PoSa), FI-38700 Kankaanpää, Finland

$13 *$ Corresponding author: Virpi Lehtoranta

15 Abstract

17 Despite growing knowledge of a disparity between stated and actual willingness to engage in pro-environmental behavior, little is known about the cognitive or attitudinal factors explaining the disparity. In the context of water quality improvement in a river basin, we address the disparity issue by applying two approaches: a typical valuation question with a hypothetical option of voluntary payment and a valuation question with a real option of voluntary payment. The latter treatment allows for further analysis of the respondents who committed to a real payment. We show empirical evidence on the psychological factors

24 explaining the disparity between the treatments and its relationship with response uncertainty.

25 The extent of learning from the survey about water management of the watershed increased 
the likelihood of stating the willingness to contribute, either with certainty or uncertainty. In turn, a previous contribution to the environmental issue, higher income, belief in the scenario, and responding to the hypothetical treatment increased the likelihood of stating certain willingness to contribute. Our findings indicate that the factors influencing the decision on the maximum payment differ between treatments. Cognitive factors, such as perceiving the valuation scenario as plausible, learning from the questionnaire, and in which mailing round the respondent completed the survey, only explained the stated amount for the willingness to pay in the treatment with a hypothetical option for voluntary payment. In the real option treatment, a higher stated willingness to pay was more likely if the respondent actually made the payment and had a higher household income.

Keywords: Contingent valuation, freshwater management, hypothetical bias, preference certainty, field study, real donation

\section{Introduction}

The contingent valuation method (CVM) has been applied in many environmental contexts to estimate the monetary value of changes in non-marketed environmental quality or quantity. The method is based on the theory of utility maximization of consumers (see e.g. Alberini and Kahn 2006; Mitchell and Carson 1993), and allows for the elicitation of willingness to pay (WTP) for a particular environmental change, such as an improvement in the water quality of a watershed. WTP is elicited with the help of a survey and a hypothetical market setting. The hypothetical market refers to 
the definition of the water quality improvement (a good for sale), the actual measures that would provide the improvement in a specified water basin, and the type of payment. The maximum WTP reflects the benefit derived by the respondent from the environmental improvement (Alberini and Kahn 2006).

In a stated preferences valuation question, especially in a CVM survey, respondents are not actually bound to paying the amount they state they are willing to pay. This may introduce hypothetical bias if a respondent perceives the valuation scenario to be too hypothetical or unrealistic and acts accordingly (Kling et al. 2012; Moser et al. 2014; Newell and Swallow 2013; Schlapfer and Fischhoff 2012). The validity of hypothetical stated WTPs has been tested for private or public goods in field and laboratory settings by offering one subsample of respondents an option for real payments and another subsample an option for standard hypothetical payments, and then comparing the results (Foster et al. 1997; List and Gallet 2001; Little and Berrens 2004; Murphy et al. 2005). As the majority of previous studies have been implemented in laboratory settings and/or focused on a private instead of a public good (e.g. Blumenschein et al. 1997; Frykblom 1997; Neill et al. 1994; Spencer et al. 1998), less information is available on the comparison of real and hypothetical willingness to pay estimates related to a public or quasi-public good, 
performed under field circumstances. In addition, little research has been conducted on whether this hypothetical bias influences people differently (Bishop and Barber 2014; Murphy and Stevens 2004).

Meta-analyses of hypothetical bias (List and Gallet 2001; Little and Berrens 2004; Murphy et al. 2005) have reported that respondents overstate their willingness to pay by a factor of 2 to 3 in hypothetical compared to real settings. The underlying reasons for the divergence between real and hypothetical WTP have been investigated since the 1990s. For instance, it has been argued that hypothetical bias may stem from free-riding behavior, where respondents rely on others to pay, even though they positively value the good and would pay something given the knowledge that the good would definitely not be provided without such payment (Brown et al. 1996). Hence, regarding voluntary contributions, for example, an initial "yes" response in a hypothetical survey helps to set up a later opportunity to free ride with respect to the actual contribution (Carson and Groves 2007). In the case of a nonvoluntary payment (e.g. tax) in combination with a single dichotomous choice question, hypothetical bias may occur if the respondent thinks that the outcome of the survey will have no influence (inconsequentiality, see e.g. Vossler et al. 2012; Vossler and Watson 2013). 
Although an extensive body of literature provides clues to some of the factors contributing to hypothetical bias in relation to public goods and field studies (see e.g. Little and Berrens 2004; Murphy et al. 2005), few studies have explored explanatory factors with regression models, simultaneously for actual payment and contingent donation treatments. Champ and Bishop (2001) modeled the factors affecting the decision to hypothetically donate, finding them to be similar to those affecting the decision to make a real donation. Furthermore, they demonstrated the elimination of hypothetical bias when the positive responses of less certain respondents were recoded to negative responses. Brown et al. (1996) observed that WTP for the removal of roads on the North Rim of the Grand Canyon was lower among older people in the hypothetical treatment alone, and was higher among people who had visited the Grand Canyon only in the actual treatment. Loomis et al. (1996) reminded participants to act as if they were in a real market situation with a real budget, and this aided them in behaving more like they would do in an actual cash market.

Ways of reducing hypothetical bias have also been examined by different approaches that aim to control preference uncertainty (see e.g. Blomquist et al. 2009; Little and Berrens 2004; Ready et al. 2010), since it has been shown that more certain WTP responses are closer to real WTP. Determinants of the sources of respondent uncertainty about their true values 
have included insufficient interest or the amount of mental effort respondents have put into responding (Hanley et al. 2009; Svedsater 2007), the bid level (Brouwer 2011; Loomis and Ekstrand 1998), prior knowledge or familiarity with the resource (Hanley et al. 2009; Loomis and Ekstrand 1998; Voltaire et al. 2013), believing in the good and/or policy instrument proposed (Akter et al. 2009; Voltaire et al. 2013), and household income (Brouwer 2011; Hanley et al. 2009; Voltaire et al. 2013).

Despite growing knowledge of a disparity between stated and actual willingness to engage in pro-environmental behavior, there is a need to understand the cognitive and attitudinal factors explaining this disparity and its relation to response uncertainty. This paper contributes to current knowledge on these factors affecting willingness to contribute and the stated WTP amounts in different survey contexts. The empirical field experiment was designed to derive benefit estimates related to an improvement in the water quality ${ }^{1}$ and hydrology of a river basin resulting from the implementation of a river basin management plan according to the European Water Framework Directive (WFD, European Parliament 2000). The empirical data consist of watershed valuation information collected in three ways: through hypothetical donations with either a hypothetical or a real option to pay, and through

\footnotetext{
${ }^{1}$ With the objective to achieve a good ecological and chemical status to protect human health, the water supply, natural ecosystems, and biodiversity.
} 
observable, real donations. This allowed us to analyze the effect of factors specific to the valuation question on the stated WTP amounts and actual payments, and thus to shed more light on the relationship between the real and hypothetical WTP and related uncertainty. Moreover, the actual payments were compared with the stated WTP in hypothetical and real option settings.

The following section presents the empirical application and the data collection. The third section presents the results of the models, and the final section discusses our findings and concludes.

\section{The application}

\subsection{Study area}

The study area, the River Kalimenjoki watershed in the region of North Ostrobothnia in Finland, is covered by a national water management plan. The river is 35 kilometers long, originating in the southeastern peat production areas of the region and flowing into the Gulf of Bothnia, the northern part of the Baltic Sea (see Figure 1). Due to the high concentration of phosphorus and occasional acidity, the ecological status of the river is classified as poor. The River Kalimenjoki is defined as a valuable small watercourse mostly located in a peri-urban area 
and with 12,000 people living in the watershed. Sixty percent of the watershed area of $224 \mathrm{~km}^{2}$ is comprised of forestland. Of the 27 lakes in the area, the two largest are Hämeenjärvi (1.04 $\left.\mathrm{km}^{2}\right)$ and Jäälinjärvi $\left(0.93 \mathrm{~km}^{2}\right)$.

[Figure 1 near here]
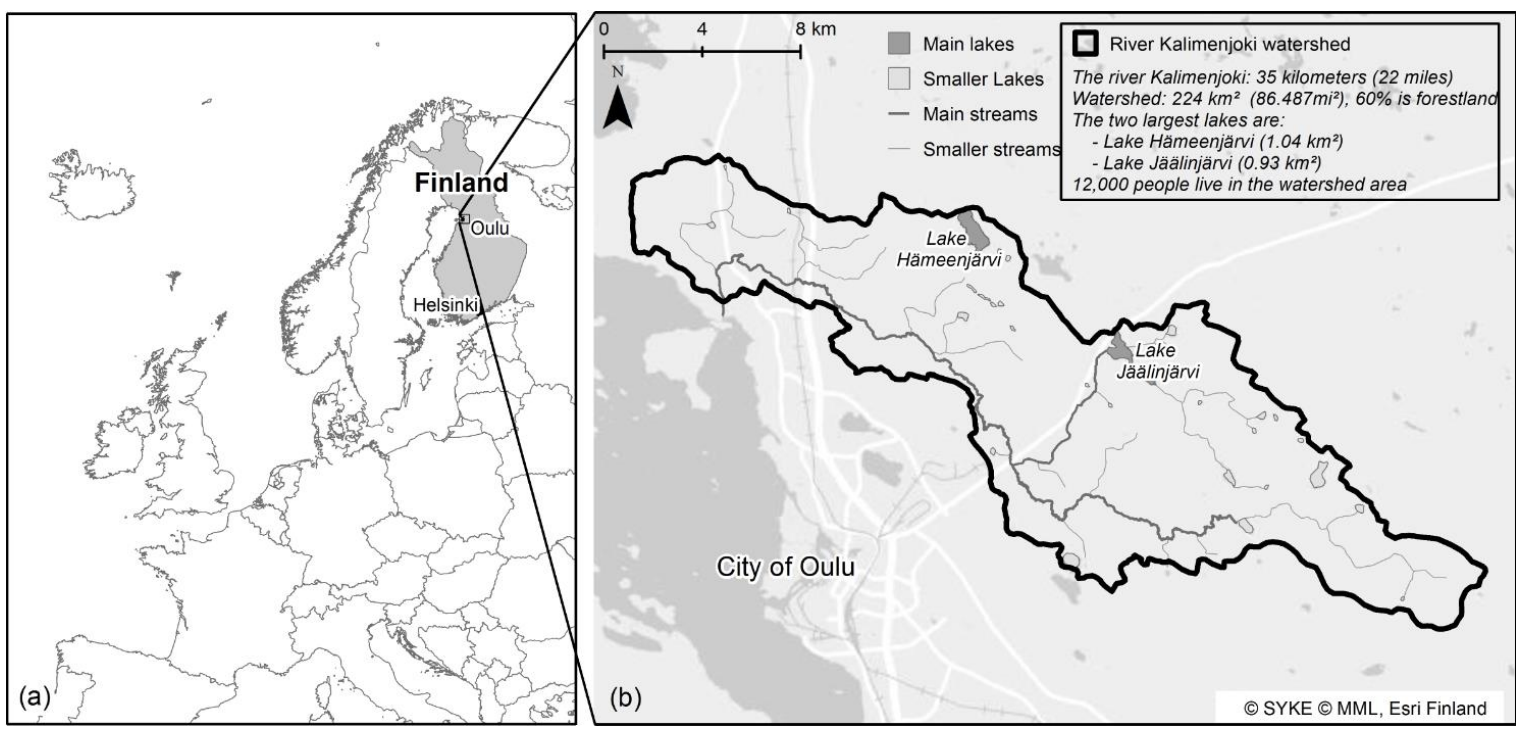

Fig. 1

Map of the study area.

\subsection{Questionnaire and valuation questions}

The questionnaire included sections describing major concerns in relation to water management, the current water state and a description of the proposed restoration option for the Kalimenjoki river basin in 2021 (valuation scenario), value elicitation questions, and follow-up and debriefing questions about the idea of contributing, possible difficulties in choosing the payments, and belief in the presented scenario. The final part of the survey contained questions about 
respondents' socio-demographic and economic household characteristics. Two scenarios for the demand assessment were defined based on the sub-basin management plan and in cooperation with two local water management associations recently established in the river basin area. The survey was pretested in a pilot phase with 13 respondents, resulting in minor changes to the final questionnaire.

The valuation research frame involved two treatments. Treatment 1 represented a traditional contingent valuation question that offered the respondents a hypothetical option to make a "voluntary water management payment". In treatment 2 , households had an option to make a real payment. At the beginning of the valuation section, the households were asked whether they would be willing to pay a one-time water management payment to one of the two water management associations with the following question:

Q8. Would you be willing to pay a water management donation for the Kellonkylä association OR the Kiiminki-Jääli water management association to implement the formerly presented water improvement plans (i.e. visions)?

$\square$ Yes

$\square$ Yes, possibly

$\square$ No $\$ You may proceed directly to question number 11 .

Up to this point, the questionnaires for the two treatments were similar. In the second part of the valuation question, only applying to those respondents who responded 'Yes' or 'Yes, possibly' to the previous question, the respondents 
were provided two alternative ways of stating their willingness to pay: a classic single-value open-ended question and, in order to reduce valuation uncertainty and to produce confidence intervals for the willingness to pay, an interval open-ended question (see e.g. Hakansson 2008). The valuation questions were identical, with the exception that in the hypothetical (HYPO) treatment, the recipient was asked "if your household had the possibility to make a one-time donation...", while in the REAL OPTION treatment, the question was framed as "now your household has the possibility to make a one-time donation..." Moreover, in the REAL OPTION treatment, the respondents were given practical instructions on how to make the donation (see Appendix A). similar settings as possible, for instance the time periods for the behavioral intent (the HYPO subsample) and for the actual behavior (the REAL OPTION subsample and those who actually paid). Donation has been proposed as a practical payment vehicle, as it offers a plausible means of providing small-scale public goods (Byrnes et al. 1999) and makes validation against actual behavior relatively easier (Champ and Bishop 2001). However, its incentive compatibility has been questioned (Carson and Groves 2007). As a consequence of free-riding, i.e. when the respondent perceives that the cost will be covered by other donations, the actual cash donations will underestimate Hicksian measures of WTP (Macmillan et al. 
1999). The one-time payment vehicle was chosen because of practicality: it was seen as the most realistic and policy-relevant means for comparing the hypothetical and real WTP for the two water management associations ${ }^{2}$.

Although the open-ended (OE) WTP question format is not preferred over dichotomous choice (DC) or other formats $^{3}$, it has been shown to provide a more accurate prediction of actual behavior than the DC question format (Hakansson 2008; Poe and Vossler 2002). Hence, both the single-value and interval OE question formats were chosen as the methods for eliciting WTP. As we applied the same question format to elicit the hypothetical and real WTP, the difference in WTP should be due to the hypothetical nature of the contingent valuation method.

The mail survey was sent by post out to 1,632 randomly selected households across the Kalimenjoki river basin in October 2012. Both treatments included 816 households. The survey practice followed Dillman's (2007) "total design method", involving a booklet questionnaire and four contacts, including the first mailing of the questionnaire, a postcard reminder, a second mailing of the questionnaire, and an additional follow-up questionnaire to those respondents in the REAL OPTION treatment who stated that they were willing to contribute, but did

\footnotetext{
${ }^{2}$ Several studies have investigated donation payment mechanisms (see e.g. Brown et al. 1996; Byrnes et al 1999; Duffield and Patterson 1992; Navrud 1992).

${ }^{3}$ See, for example, the opinion of the famous blue-ribbon panel - assembled by NOAA- who assessed the reliability of CV methods (Arrow et al. 1993).
} 
not actually do so. The sampling was carried out by the Finnish Environment Institute and the Finnish Population Register Centre based on Finnish Census data from 2011.

\section{Results}

The final response rate was similar in both treatments, $31 \%$, as the data collection ended with 505 complete responses: 253 in the HYPO subsample and 252 in the REAL OPTION subsample. Hence, and interestingly, giving the respondents a real option to pay did not have a decreasing effect on the response rate. Although response rates were moderate, they were very close to our prior expectation: the desired number of responses $(\mathrm{N}=263$ per treatment) was calculated using a confidence level of 95\%, a margin of error $5 \%$, and population of 12,000 .

\subsection{Descriptive statistics for the data}

Table 1 presents descriptive statistics for the data with regard to socio-demographic information, experience, and answering of the valuation questions, and a comparison of respondents in the treatments with the independent samples ttests and nonparametric tests. The proportion of females, average age of the respondents, household income, and the average distance of the respondents' homes from the nearest lake or river did not differ statistically significantly between the HYPO and REAL OPTION treatments. Regarding the experience of water 
resources or their management and the socio-demographic characteristics, the data sets were similar. The majority of respondents $(53 \%$ and $52 \%$ in hypothetical and real intention treatments, respectively) learnt from the questionnaire about freshwater management in the area $(L E A R N)$. Almost half of the respondents (46/43\%) had visited a lake or riverside for recreational purposes (USER). A clear minority $(9 \% / 8 \%)$ had participated in voluntary water management work (VOLUN) and/or paid a subscription fee to the water management association (11\%/11\%) (SUBSCRIPT). In conclusion, the respondents were fairly familiar with the public good being 302 valued, and the similarity between the data sets in sociodemographic terms was sufficient to allow a comparison of the WTP results between treatments.

Some statistically significant differences were found in relation to the answers to valuation questions. Although the share of respondents who responded in the first mailing round was similar $(68 \%$ and $71 \%$ in hypothetical and real 309 intention treatments, respectively), stating the maximum donation was perceived as easier $(E A S E)$ in the REAL OPTION treatment $(60 \%)$ than in the HYPO treatment $(48 \%)$. A larger share of respondents in the hypothetical treatment (51\%) than in the real option treatment $(41 \%)$ perceived the scenario to be plausible (TRUST). Moreover, a larger share of respondents in 
(29\%) expressed uncertainty over whether to contribute to the program (UNCERT), but this difference was not statistically significant.

As only a fraction of REAL OPTION participants actually paid, statistical comparisons based on the descriptive statistics should be interpreted with caution. However, the results indicated several statistically significant differences in relation to the third subsample, i.e. actual donors (Table 1).

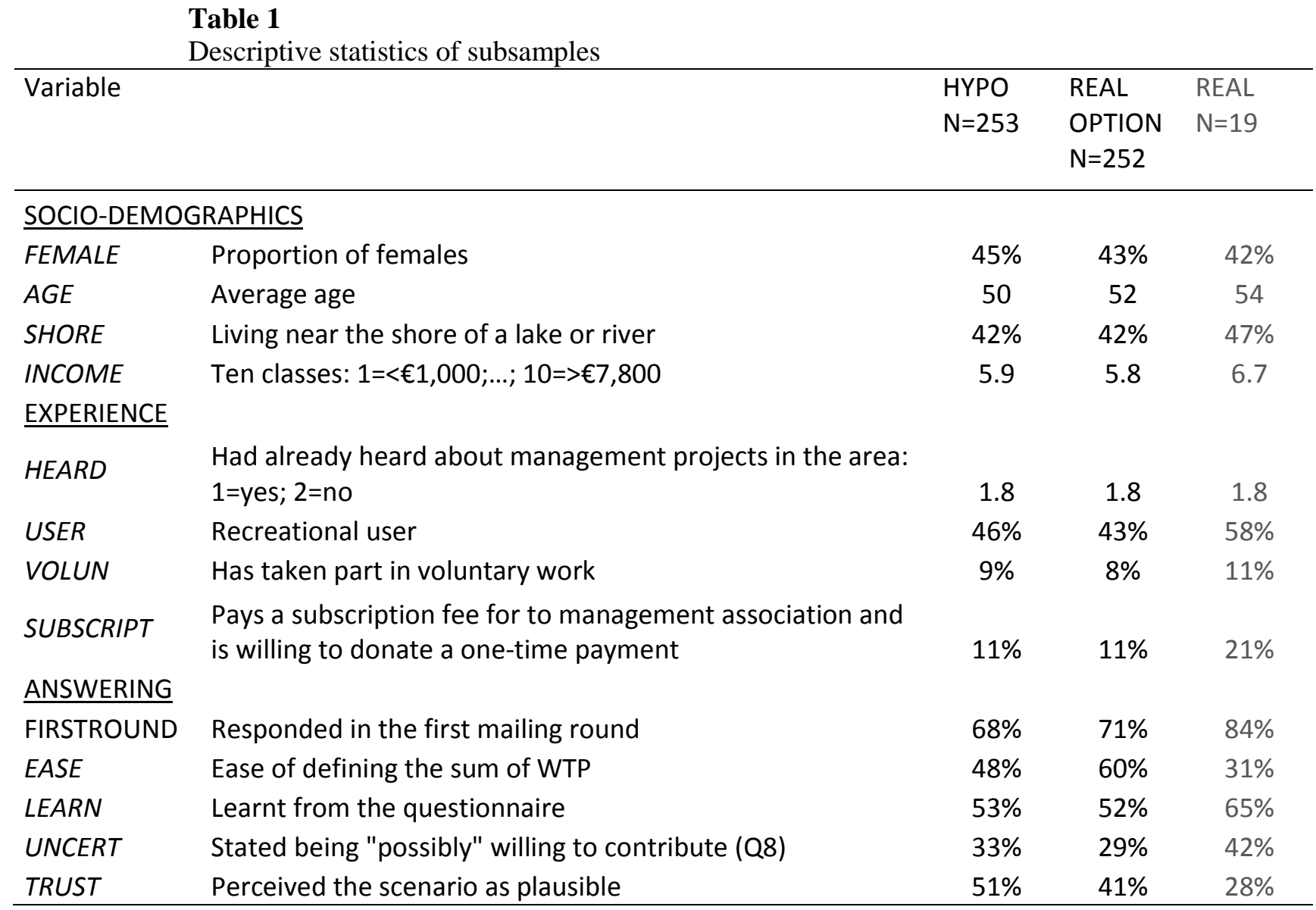


In the pooled data set for the two treatments, the

332

333

334

335

336

337

338

339

340

341

342

343

344

345

346

347

348

349

350

351

352

353

354

355 majority of the respondents $(55 \%)$ refused to pay $\left(\mathrm{n}_{\mathrm{yes}}=60, \mathrm{n}_{\mathrm{yes}}\right.$, possibly $=151, \mathrm{n}_{\mathrm{no}}=259$ ). Table 2 presents the proportions of respondents who were willing to contribute to the association (Question 8 in the questionnaire), those who stated their WTP in euros (Question 9 in the questionnaire, see Appendix A), and the share of actual payments in the REAL OPTION treatment. The number of respondents stating willingness to contribute was higher in the HYPO (15\%) than in the REAL OPTION treatment (9\%). In addition, $33 \%$ and $29 \%$ of respondents in the HYPO and REAL OPTION treatments, respectively, stated that they were possibly willing to contribute. Almost two-fifths (38\%) of the respondents in the HYPO sample and one-fifth (21\%) in the REAL OPTION treatment stated their WTP in euros. Only $8 \%$ of the respondents in the REAL OPTION treatment actually donated the payment through a bank transfer. Although these respondents had quite evenly answered "yes" (YES) or "yes, possibly" (PYES) to question 8, this proportion was close to the share of those respondents who were without a doubt ready to contribute $(9 \%)$. The decision to state a positive payment varied among "yes, possibly" contributors in the two treatments: $71 \%$ and $40 \%$ of these respondents in the HYPO and REAL OPTION treatments, respectively, stated a positive payment.

Table 2 
The proportions of respondents willing to contribute and stating a positive payment out of all respondents in the HYPO and REAL OPTION treatments and in the pooled data set

\begin{tabular}{|c|c|c|c|c|}
\hline \multirow[t]{2}{*}{ Treatment } & \multicolumn{2}{|c|}{$\begin{array}{l}\text { Willingness to } \\
\text { contribute }(\mathrm{Q} 8)\end{array}$} & \multirow{2}{*}{$\begin{array}{l}\text { Out of the } \\
\text { "contributors" } \\
\text { (Q8) who } \\
\text { chose to pay } \\
(\mathrm{Q} 9) \\
\text { Stated a } \\
\text { payment }\end{array}$} & \multirow{2}{*}{$\begin{array}{l}\text { Real } \\
\text { payment }\end{array}$} \\
\hline & $\mathrm{YES}^{1}$ & $\mathrm{PYES}^{1}$ & & \\
\hline $\begin{array}{l}\text { HYPO } \\
(n=253)\end{array}$ & $15 \%$ & $33 \%$ & $38 \%$ & n.a. \\
\hline $\begin{array}{l}\text { REAL } \\
\text { OPTION } \\
(n=252)\end{array}$ & $9 \%$ & $29 \%$ & $21 \%$ & $8 \%$ \\
\hline $\begin{array}{l}\text { REAL } \\
(n=19)\end{array}$ & $58 \%$ & $42 \%$ & $100 \%$ & $100 \%$ \\
\hline $\begin{array}{l}\text { POOLED } \\
(\mathrm{n}=505)\end{array}$ & $12 \%$ & $31 \%$ & $30 \%$ & n.a. \\
\hline
\end{tabular}

3.3 Factors associated with willingness to contribute and related response uncertainty detailed description of the model) were constructed with the aim to reveal the factors associated with the stated willingness to contribute and related response uncertainty. The dependent variables referred to whether the respondent was willing (YES) or possibly willing (UNCERT) to make a non-zero payment. In the first model, the dependent variables take the value of one when the respondent is definitely willing to contribute ("yes, possibly" and "no" respondents counted as not willing to pay), and in the second model when the respondent is uncertain, i.e. 
counted as not having uncertainty in the decision to pay). Table 3 presents the results estimated using the statistical software NLOGIT5.

The results of the first logit model show that definite willingness to contribute significantly correlated with six variables: already paying a subscription fee for a water management association (SUBSCRIPTION), a higher household income (HHINCOME), learning from the questionnaire $(L E A R N)$, not responding in the REAL OPTION treatment (REAL OPTION), perceiving the scenario to be plausible (TRUST), and having difficulty in defining the maximum sum of WTP (EASE).

The results of the second logit model for factors influencing uncertainty related in the decision to make a positive payment are also reported in Table 3. Notably, higher uncertainty was significantly correlated with the stated difficulty in revealing the household's WTP (EASE) indicating an increasing amount of mental effort put into responding. Responding in the first mailing round (FIRSTROUND), and learning from the questionnaire $(L E A R N)$ also increased the uncertainty of respondents. However, the household's income and whether the respondent answered in either the HYPO or REAL OPTION treatment, or being a member of a water management association, did not influence the respondent's uncertainty (HHINCOME, REAL OPTION, SUBSCRIPTION). 
400

401

402

403

404

405

406

407

408

409

410

These results partly contradict those of Hanley et al. (2009), who showed that experience of the good, a higher income, and an increasing amount of mental effort put into responding may explain increased uncertainty over the value people place on public goods.

\begin{tabular}{|c|c|c|c|}
\hline \multicolumn{2}{|c|}{ Variable descriptions } & \multirow{2}{*}{$\begin{array}{c}\text { YES } \\
(0-1) \\
\text { Coefficient } \\
\text { (Std. Error) } \\
\end{array}$} & \multirow{2}{*}{$\begin{array}{c}\text { UNCERT } \\
(0-1) \\
\text { Coefficient } \\
\text { (Std. Error) } \\
\end{array}$} \\
\hline & & & \\
\hline Constant & & $-2.24(1.47)$ & $-1.14(1.01)$ \\
\hline GENDER & Female (1); male (2) & $-0.09(0.01)$ & $0.10(0.25)$ \\
\hline$A G E$ & $18-75 \mathrm{yrs}$ & $-0.01(0.01)$ & $-0.01(0.01)$ \\
\hline USEVALUE & Uses waters for recreation (1); otherwise (0) & $0.56(0.40)$ & $0.33(0.26)$ \\
\hline HHINCOME & Household's average monthly income, ten classes & $0.17(0.08)^{* *}$ & $-0.01(0.01)$ \\
\hline KNOWLEDGE & $\begin{array}{l}\text { Had already heard about the river basin management plan } \\
\text { (1); otherwise (0) }\end{array}$ & $-0.37(0.46)$ & $0.18(0.32)$ \\
\hline SUBSCRIPTION & $\begin{array}{l}\text { Pays a subscription fee to a water management association } \\
\text { (1); otherwise (0) }\end{array}$ & $1.12(0.44)^{* *}$ & $-0.48(0.37)$ \\
\hline ATTITUDE & $\begin{array}{l}\text { Restoration of small waters: very important }(1), \ldots, \text { very } \\
\text { unimportant (5) }\end{array}$ & $-0.37(0.46)$ & $0.04(0.22)$ \\
\hline INTEREST & $\begin{array}{l}\text { Detached the first page (information about the water } \\
\text { management associations) of the survey to her/himself (1); } \\
\text { otherwise (0) }\end{array}$ & $-0.01(0.37)$ & $0.05(0.26)$ \\
\hline REAL OPTION & $\begin{array}{l}\text { Responded in the REAL OPTION treatment (1); in the HYPO } \\
\text { treatment (0) }\end{array}$ & $0.81(0.38)^{* *}$ & $0.16(0.25)$ \\
\hline FIRSTROUND & Responded in the first mailing round (1); otherwise (0) & $0.02(0.41)$ & $0.65(0.28)^{* *}$ \\
\hline TRUST & Perceived the scenario to be plausible (1); otherwise (0) & $0.78(0.39)^{* *}$ & $0.16(0.26)$ \\
\hline LEARN & Learnt from the questionnaire (1); otherwise (0) & $0.91(0.42)^{* *}$ & $0.57(0.27)^{* *}$ \\
\hline EASE & Ease of defining the sum of WTP (1); otherwise (0) & $-0.68(0.39)^{*}$ & $-1.38(0.26)^{* * *}$ \\
\hline & $\mathrm{N}$ & 337 & 337 \\
\hline & Chi squared [13 d.f.] & $60.50 * * *$ & $52.49 * * *$ \\
\hline & McFadden pseudo $\mathrm{R}^{2}$ & 0.22 & 0.12 \\
\hline
\end{tabular}

Table 3

Estimated coefficients for two logit models of i) the definite certainty of a respondent in being willing to make a one-time donation to the water management association and ii) related response uncertainty 

who reported willingness to contribute stated their payment with a single-value open-ended (OE) valuation question, while the rest chose the alternative type, i.e. an interval OE valuation question. Examining this issue from the actual payment viewpoint, the majority of respondents who actually made the payment in the REAL OPTION treatment had stated their maximum WTP with the single-value OE question, and those who stated their payment with the interval open-ended question paid along their upper bound payment. Therefore, the mean WTPs were calculated using the payments stated with the single-value OE answers and the upper bound payments of an interval OE question.

The effect of socio-economic and attitudinal factors on the stated WTP was analyzed with a linear OLS regression model. The type of valuation question and motivational factors were accounted for in the fourth model (POOLED, WTP > 0). The results of the models are presented in Table 4 .

Table 4

Linear OLS regression analysis of the factors affecting single-value and interval OE statements for WTP. Dependent variable: [ln (WTP+1)]

Variable

\begin{tabular}{llll}
\multicolumn{4}{c}{ Model } \\
\hline HYPO & REAL & REAL & POOLED, \\
& OPTION & & WTP $>0$
\end{tabular}




\begin{tabular}{|c|c|c|c|c|c|}
\hline & & $\mathrm{t}$ & $\mathrm{t}$ & $\mathrm{t}$ & $\mathrm{t}$ \\
\hline Constant & & $2.55^{* *}$ & 1.47 & 0.64 & $3.28 * * *$ \\
\hline GENDER & & 0.18 & -0.98 & - & 0.21 \\
\hline$A G E$ & & -2.24 & -0.63 & -0.22 & 0.20 \\
\hline USEVALUE & & 0.77 & 0.78 & -0.64 & 1.16 \\
\hline HHINCOME & & 1.27 & $2.22 * *$ & -0.15 & $1.68 *$ \\
\hline KNOWLEDGE & & -0.46 & 0.00 & -0.64 & 0.56 \\
\hline SUBSCRIPTION & & $2.16^{* *}$ & $2.28^{* *}$ & $4.09 * * *$ & 1.40 \\
\hline ATTITUDE & & -1.58 & 0.10 & -0.64 & -1.52 \\
\hline INTEREST & & 0.93 & -0.93 & -1.11 & $1.80^{*}$ \\
\hline REAL OPTION & & - & - & - & $-1.77^{*}$ \\
\hline FIRSTROUND & & $1.91 *$ & 1.60 & 0.77 & 0.47 \\
\hline TRUST & & $2.68 * * *$ & 1.45 & -1.23 & 1.16 \\
\hline LEARN & & $\begin{array}{c}2.32^{* *} \\
-\end{array}$ & -0.05 & 1.36 & -0.35 \\
\hline EASE & & $4.47^{* * *}$ & $-6.23 * * *$ & $3.32 * *$ & -0.92 \\
\hline PAID & & - & $6.59 * * *$ & - & - \\
\hline INTERVAL & & - & - & -0.32 & $2.31 * * *$ \\
\hline WATERQUALITY & & - & - & -0.57 & -1.04 \\
\hline IMPORTANCE & & - & - & -0.58 & $2.25^{* *}$ \\
\hline & $\mathrm{N}$ & 164 & 120 & 19 & 124 \\
\hline & $\mathrm{R}^{2}$ & 0.43 & 0.62 & 0.98 & 0.32 \\
\hline
\end{tabular}

Two statistically significant variables associated with a higher willingness to pay statement are common between the HYPO and REAL OPTION treatments. First, the negative coefficient of the variable EASE indicated that respondents who perceived the maximum sum of WTP as being difficult to 445 define were more likely willing to pay a higher sum than those who perceived this to be easy. This factor was also significant for the likelihood of being willing to contribute. Second, the positive sign of the variable SUBSCRIPTION indicated that those respondents who were already members of either river management association were more willing to pay a higher sum than non-members. 
Interestingly, the respondent's gender or age, using waters for recreation (USEVALUE), and attitude towards the

454

455

456

457

458

459

460

461

462

463

464

465

466

467

468

469

470

471

472

473

474

475

476 restoration of small waters (ATTITUDE) were not related to the

amount of the payment in regression models for either treatment. Cognitive factors, e.g. perceiving the valuation scenario as plausible (TRUST), learning from the questionnaire (LEARN), and the mailing round in which the participant responded to the survey (FIRSTROUND), explained the stated amount for the WTP only in the HYPO treatment. In the REAL OPTION treatment, a higher stated WTP more probably resulted if the respondent actually made the payment (PAID) and had a higher household income (HHINCOME).

The results from the fourth pooled model with positive WTPs indicated that the stated amount for the WTP increased with the use of an interval OE WTP valuation question (INTERVAL) and when validating the positive payment with the importance of the valuation scenario (IMPORTANCE). Furthermore, responding in the HYPO treatment (REAL OPTION), a higher household income (HHINCOME), and greater interest (INTEREST) associated with a higher WTP.

3.5 Mean WTP amounts, ratios, and aggregation of the benefits On average, the respondents were willing to pay $€ 33$ in the HYPO treatment and $€ 17$ in the REAL OPTION 
treatment, including the respondents who stated zero WTP. Thus, the hypothetical to real intention ratio is 1.9 . Before the analysis, two outliers, identified as having paid amounts that exceeded $€ 999$, were removed. There was statistical evidence of an overall difference in the mean donations between the HYPO and REAL OPTION treatments (independent-samples $t$-test: $t=3.229$, $p=0.001 ; t=2.435, p=0.015)$. Out of 252 respondents for the REAL OPTION treatment, 51 stated some positive payment in the survey. Of these, 19 (37\%) actually made a donation. Next, we compared the stated amounts of WTP in the REAL OPTION treatment with those payments actually made to the associations. The REAL OPTION:REAL ratio was 2.8 , whereas the HYPO:REAL ratio was 5.5. Table 5 reports the mean WTPs for the two treatments and the average of the actually paid donations for those who responded in the REAL OPTION treatment.

\section{Table 5}

The mean willingness to pay estimates (EUR per household in October 2012) for the HYPO and REAL OPTION treatments and the average of the actually paid donations in the REAL treatment (and standard deviations of the mean WTPs in parentheses)

\begin{tabular}{lccccc}
\hline \multirow{2}{*}{ Treatment } & \multicolumn{2}{c}{ Stated willingness to pay } & & \multicolumn{2}{c}{ Actual payment } \\
\cline { 2 - 3 } \cline { 5 - 6 } & Per contributor & Per respondent & & Per contributor & Per respondent \\
\hline \hline HYPO & $€ 75(106.9)$ & $€ 33(80.0)$ & & n.a. & n.a. \\
REAL OPTION & $€ 60(77.8)$ & $€ 17(49.4)$ & & $€ 80(115.5)$ & $€ 6(27.3)$ \\
\hline
\end{tabular}

An aggregate benefit estimate was calculated by multiplying the pooled average household WTP estimate by the number of households in the municipality of the study area, i.e. 
503

504

505

506

507

508

509

510

511

512

513

5,600. When determining the sample mean WTP, the mean WTP values of non-respondents were assumed to be $49 \%$ of the values for respondents. This was due to the difference in the data, as the mean WTP differed between respondents replying to the first and second mailing $(64 \% / 36 \%$, the variable FIRSTROUND), being $€ 31.7$ and $€ 12.5$, respectively. Thus, households of the region would be willing to pay a one-time water management payment of EUR 93,000 in total to the water associations of Kellonkylä or Kiiminki-Jääli. 
514

515

516

517

518

519

520

521

522

523

524

525

526

527

528

529

530

531

532

533

534

535

536

537

538

\subsection{Inconsequentiality}

To investigate the reasons underlying the hypothetical bias and whether inconsequentiality had played any role in it, the motivations for not paying are investigated with a follow-up questionnaire including seven alternative options explaining the difference in the stated willingness to pay and the actual payment. The follow-up questionnaire (see Appendix B) was sent to the 34 respondents in the REAL OPTION treatment who had not actually paid. Based on $13(38 \%)$ completed and returned questionnaires, the following reasons were identified: some respondents had paid the annual subscription to the local association, other respondents first wanted to be sure that the other residents would also pay, and one respondent had changed his mind because he thought that polluters should pay all the costs of water management. Furthermore, two respondents paid the donation later. Based on this analysis, we cannot identify a lack of belief in the influence of the survey on policy makers among the majority of respondents.

\section{Discussion}

Offering respondents a possibility for real payment makes a valuation scenario more realistic, as it allows respondents to contribute in real monetary terms. Moreover, a more careful consideration of whether to state a positive 
willingness to pay could be expected, with a consequent reduction in hypothetical bias. The analysis in this paper confirmed this expectation, reflected by a lower proportion of stated contributions among respondents in the REAL OPTION treatment $(9-21 \%)$ in comparison to the HYPO treatment (15$38 \%$ ). Using the proportion of YES responses out of all responses (including possible YES responses and NO responses) to the question concerning willingness to contribute (Q8) offered a simple way to estimate the minimum number of welfare gainers, since only $8 \%$ of the respondents actually donated a water management payment ${ }^{4}$ in the REAL OPTION treatment.

This paper provides new empirical evidence on the explanatory factors of the willingness to contribute and the related response certainty. The extent of learning about water management from the survey increased the likelihood of stating a willingness to contribute, either with certainty or uncertainty. In turn, responding immediately to the survey (during the first mailing round) and the perceived difficulty in stating the WTP amount (implying the difficulty of the task for the respondent) increased the likelihood of stating an uncertain willingness to contribute. In turn, previous contribution to the environmental issue, a higher income, belief in the scenario, and responding to

\footnotetext{
${ }^{4}$ However, not every yes response revealed actual payment, and there were also actual payers among the "yes, possibly" responses.
} 
the HYPO treatment increased the likelihood of stating a certain

563

564

565

566

567

568

569

570

571

572

573

574

575

576

577

578

579

580

581

582

583

584

585

willingness to contribute.

Earlier studies have indicated a clear divergence between hypothetical willingness to pay and actual payments in stated preference valuation in both laboratory studies and field circumstances (e.g. Foster et al. 1997; List and Gallet 2001). Based on a meta-analysis, Murphy et al. (2005) argued that the calibration factor varies between two and three. The calibration factor calculated from this study, 1.9 in the hypothetical and real intention payment treatments, is close to their findings. When only including the actual payers of our sample in comparisons, the calibration factor between the average WTP in the HYPO treatment and the actual payment was 5.5. These results are in line with earlier studies and closest to the results presented by Brown et al. (1996).

Consistent with the outcome obtained by Duffield and Patterson (1992), the mean WTPs of the respondents with a positive WTP were rather similar across hypothetical (€75) and real (€60) treatments. Interestingly, the mean WTP estimate of actual contributors in the REAL OPTION treatment $(€ 80)$ exceeded the mean WTP in the REAL OPTION treatment (€60). This result suggests that the respondents having a positive WTP had a true incentive to state their maximum WTP. It is also notable that a large share of all actual contributors 
600 stated that they were "possibly" willing to contribute some positive payment.

However, to obtain "real" sample WTP estimates closer to the Hicksian value (see e.g. Newell and Swallow 2013), methods adding realism in the "water management market" should be considered. Furthermore, the usefulness of adding questions on self-reported implementation intentions, i.e. planning when and where to pay, could be considered to define the number of "true" contributors. According to Gollwitzer (1993), individual intentions are more likely to be translated into action when an individual develops a clear scenario of the circumstances under which the pursued action is to be performed.

\section{Conclusions}

This paper provides estimates of the benefits from the improvement of water quality according to the European Union WFD using two treatments: a typical hypothetical contingent valuation question (HYPO) and a contingent valuation question with a real payment intention (REAL OPTION). Our paper compares real and hypothetical WTP estimates and dependent factors related to the improvement of freshwater quality, performed under field circumstances. The novelty of this paper is in probing the cognitive and attitudinal factors that might explain this disparity 
611

612

613

614

615

616

617

618

619

620

621

622

623

624

625

626

627

628

629

630

631

632

633

634

635

between stated and actual willingness to engage in proenvironmental behaviors. The results demonstrated a difference between the hypothetical and real intention WTP: the subtle wording changes and some instructions about paying via an Internet or local bank may move the individuals one step closer to a commitment to pay when they say they will pay.

In the water management context, further studies comparing real with hypothetical payments involving a reasonable sample size to enable statistical analyses within the real treatment would be desirable. In addition, there appears to be a common interest among cognitive psychologists and environmental economists in exploring the effect of the wording of valuation questions.

Our study, while revealing the divergences in results gathered from real intention and hypothetical treatments, did not challenge the feasibility of the contingent valuation method in valuing environmental amenities as such. However, the results highlight the need for a more thorough assessment of which respondent-related factors are associated with hypothetical bias. Although challenging to implement, further split sample and real world case studies on this subject with sufficient sample sizes are encouraged.

When provided an option to make a real payment, survey respondents stated their valuation realistically compared to their average actual donation, adding more realism to the valuation scenario. The divergence between the hypothetical and real 
644

645

646

647

648

649

650

651

652

653

654

655

656

657

658

659

660 willingness to pay evidenced in this study does not indicate whether the WTP is overstated in the hypothetical or understated in the real option treatment. Acknowledging the difference in WTP estimates in these two treatments provides an opportunity to use either estimate of the aggregate WTP as a useful measure of the actual behavioral intentions of individuals or the environmental benefits derived from water quality improvement when estimating society's demand for water quality improvements.

\section{Acknowledgements}

This research was funded by the Finnish Environment Institute, Ministry of Environment and Ministry of Agriculture and Forestry. The study also benefited from funding from the Academy of Finland (Grant no. 275772 and 1263337). The authors thank Birger Ylisaukko-oja from the Kiiminki-Jääli water management association and Reijo Tiri from the Kellonkylä association for their contributions to the planning of the survey questionnaire, and the colleagues in the Finnish society of valuation researchers (Arvoke) for useful discussions and valuable comments. The authors thank anonymous reviewers for constructive comments and suggestions on the earlier versions of this paper and Roy Siddall for editing the English. 
Akter S, Brouwer R, Brander L, van Beukering P (2009) Respondent uncertainty in a contingent market for carbon offsets Ecological Economics 68:1858-1863 doi:10.1016/j.ecolecon.2008.12.013

665

666

667

668

669

670

671

672

673

674

675

676

677

678

679

680

681

682

683

684

685

686

687

688

689

690

691

692

693

694

695

696

697

698

699

700

701

702

703

704

705

706

707

708

709

710

711

Alberini A, Kahn JR (2006) Handbook on contingent valuation. Edward Elgar Publishing Inc., Massachusetts, USA

Arrow K, Solow R, Portney PR, Leamer EE, Radner R, Schuman H (1993) Report of the NOAA panel on contingent valuation. National Oceanic and Atmospheric Administration,

Bishop MM, Barber NA (2014) Putting Your Money Where Your Mouth Is: The Value of Low Purchase Intention Consumers to Product Pricing J Prod Innovat Manag 31:908-923 doi:10.1111/jpim.12131

Blomquist GC, Blumenschein K, Johannesson M (2009) Eliciting Willingness to Pay without Bias using Follow-up Certainty Statements: Comparisons between

Probably/Definitely and a 10-point Certainty Scale Environmental \& Resource Economics 43:473-502 doi:10.1007/s10640-008-9242-8

Blumenschein K, Johannesson M, Blomquist GC, Liljas B, OConor RM (1997) Hypothetical versus real payments in Vickrey auctions Econ Lett 56:177-180 doi:Doi 10.1016/S0165-1765(97)81897-6

Brouwer R (2011) A mixed approach to payment certainty calibration in discrete choice welfare estimation Appl Econ 43:2129-2142 doi:10.1080/00036840903035977

Brown TC, Champ PA, Bishop RC, McCollum DW (1996) Which response format reveals the truth about donations to a public good? Land Economics 72:152-166 doi:Doi $10.2307 / 3146963$

Byrnes B, Jones C, Goodman S (1999) Contingent Valuation and Real Economic Commitments: Evidence from Electric Utility Green Pricing Programmes Journal of Environmental Planning and Management 42:149-166 doi:DOI:10.1080/09640569911190

Carson RT, Groves T (2007) Incentive and informational properties of preference questions Environmental \& Resource Economics 37:181-210 doi:10.1007/s10640-007-9124-5

Champ PA, Bishop RC (2001) Donation payment mechanisms and contingent valuation: An empirical study of hypothetical bias Environmental \& Resource Economics 19:383402 doi:Doi 10.1023/A:1011604818385

Dillman D, A. (2007) Mail and Internet Surveys. The Tailored Design Method. second edn. John Wiley \& Sons, Inc., New Jersey, USA

Duffield JW, Patterson DA (1992) Field Testing Existence Values: Comparison of Hypothetical and Cash Transaction Values. In: Rettig RB (ed) Benefits and Costs in Natural Resource Planning. Fifth Interim Report.

European Parliament CotEU (2000) Water Framework Directive, 2000. European Parliament and of the Council,

Foster V, Bateman IJ, Harley D (1997) Real and hypothetical willingness to pay for environmental preservation: A non-experimental comparison Journal of Agricultural Economics 48:123-138 doi:DOI 10.1111/j.1477-9552.1997.tb01140.x

Frykblom P (1997) Hypothetical question modes and real willingness to pay Journal of Environmental Economics and Management 34:275-287 doi:DOI 10.1006/jeem.1997.1015

Gollwitzer PM (1993) Goal achievement: The role of intentions. In: Stroebe W, Hewstone M (eds) European review of social psychology, vol 4. Wiley, Chichester, England, pp 141-185

Gujarati DN (2004) Basic Econometrics. Fourth edn. The McGraw-Hill Companies, 
712

713

714

715

716

717

718

719

720

721

722

723

724

725

726

727

728

729

730

731

732

733

734

735

736

737

738

739

740

741

742

743

744

745

746

747

748

749

750

751

752

753

754

755

756

757

758

759

760

761

762

763

764

765

Hakansson C (2008) A new valuation question: analysis of and insights from interval openended data in contingent valuation Environmental \& Resource Economics 39:175188 doi:10.1007/s10640-007-9102-y

Hanley N, Kristrom B, Shogren JF (2009) Coherent Arbitrariness: On Value Uncertainty for Environmental Goods Land Economics 85:41-50

Kling CL, Phaneuf DJ, Zhao JH (2012) From Exxon to BP: Has Some Number Become Better than No Number? J Econ Perspect 26:3-26 doi:10.1257/jep.26.4.3

List JA, Gallet CA (2001) What experimental protocol influence disparities between actual and hypothetical stated values? Environmental \& Resource Economics 20:241-254 doi:Doi 10.1023/A:1012791822804

Little J, Berrens R (2004) Explaining Disparities between Actual and Hypothetical Stated Values: Further Investigation Using Meta-Analysis. Economics Bulletin 3:1-13

Loomis J, Brown T, Lucero B, Peterson G (1996) Improving validity experiments of contingent valuation methods: Results of efforts to reduce the disparity of hypothetical and actual willingness to pay Land Economics 72:450-461 doi:Doi $10.2307 / 3146908$

Loomis J, Ekstrand E (1998) Alternative approaches for incorporating respondent uncertainty when estimating willingness to pay: the case of the Mexican spotted owl Ecological Economics 27:29-41 doi:Doi 10.1016/S0921-8009(97)00126-2

Macmillan DC, Smart TS, Thorburn AP (1999) A field experiment involving cash and hypothetical charitable donations Environmental \& Resource Economics 14:399-412 doi:Doi 10.1023/A:1008304405734

Mitchell RC, Carson RT (1993) Using Surveys to Value Public Goods: The Contingent Valuation Method. Third edn. Resources for the Future, 1616 P Street, N.W., Washington, D.C. 20036

Moser R, Raffaelli R, Notaro S (2014) Testing hypothetical bias with a real choice experiment using respondents' own money European Review of Agricultural Economics 41:25-46 doi:10.1093/erae/jbt016

Murphy JJ, Allen PG, Stevens TH, Weatherhead D (2005) A meta-analysis of hypothetical bias in stated preference valuation Environmental \& Resource Economics 30:313325 doi:DOI 10.1007/s10640-004-3332-z

Murphy JJ, Stevens TH (2004) Contingent Valuation, Hypothetical Bias, and Experimental Economics Agricultural and Resource Economics Review 33:182-192

Navrud S (1992) Willingness to pay for preservation of species: an experiment with actual payments. In: Navrud S (ed) Pricing the European Environment. Oxford University Press, New York, pp 231-246

Neill HR, Cummings RG, Ganderton PT, Harrison GW, Mcguckin T (1994) Hypothetical Surveys and Real Economic Commitments Land Economics 70:145-154 doi:Doi $10.2307 / 3146318$

Newell LW, Swallow SK (2013) Real-payment choice experiments: Valuing forested wetlands and spatial attributes within a landscape context Ecological Economics 92:37-47 doi:10.1016/j.ecolecon.2012.08.008

Poe GL, Vossler CA (2002) Monte Carlo benchmarks for discrete response valuation methods: Comment Land Economics 78:605-616 doi:Doi 10.2307/3146856

Ready RC, Champ PA, Lawton JL (2010) Using Respondent Uncertainty to Mitigate Hypothetical Bias in a Stated Choice Experiment Land Economics 86:363-381

Schlapfer F, Fischhoff B (2012) Task familiarity and contextual cues predict hypothetical bias in a meta-analysis of stated preference studies Ecological Economics 81:44-47 doi:10.1016/j.ecolecon.2012.06.016

Spencer MA, Swallow SK, Miller CJ (1998) Valuing Water Quality Monitoring: A Contingent Valuation Experiment Involving Hypothetical and Real Payments 27:28-42

Svedsater H (2007) Ambivalent statements in contingent valuation studies: inclusive response formats and giving respondents time to think Aust J Agr Resour Ec 51:91107 doi:10.1111/j.1467-8489.2007.00346.x 
766 Voltaire L, Pirrone C, Bailly D (2013) Dealing with preference uncertainty in contingent willingness to pay for a nature protection program: A new approach Ecological Economics 88:76-85 doi:10.1016/j.ecolecon.2013.01.009

769

Vossler CA, Doyon M, Rondeau D (2012) Truth in Consequentiality: Theory and Field Evidence on Discrete Choice Experiments Am Econ J-Microecon 4:145-171 doi:10.1257/mic.4.4.145

Vossler CA, Watson SB (2013) Understanding the consequences of consequentiality: Testing the validity of stated preferences in the field J Econ Behav Organ 86:137-147 doi:10.1016/j.jebo.2012.12.007 
Appendix A. Valuation question in the two separate questions

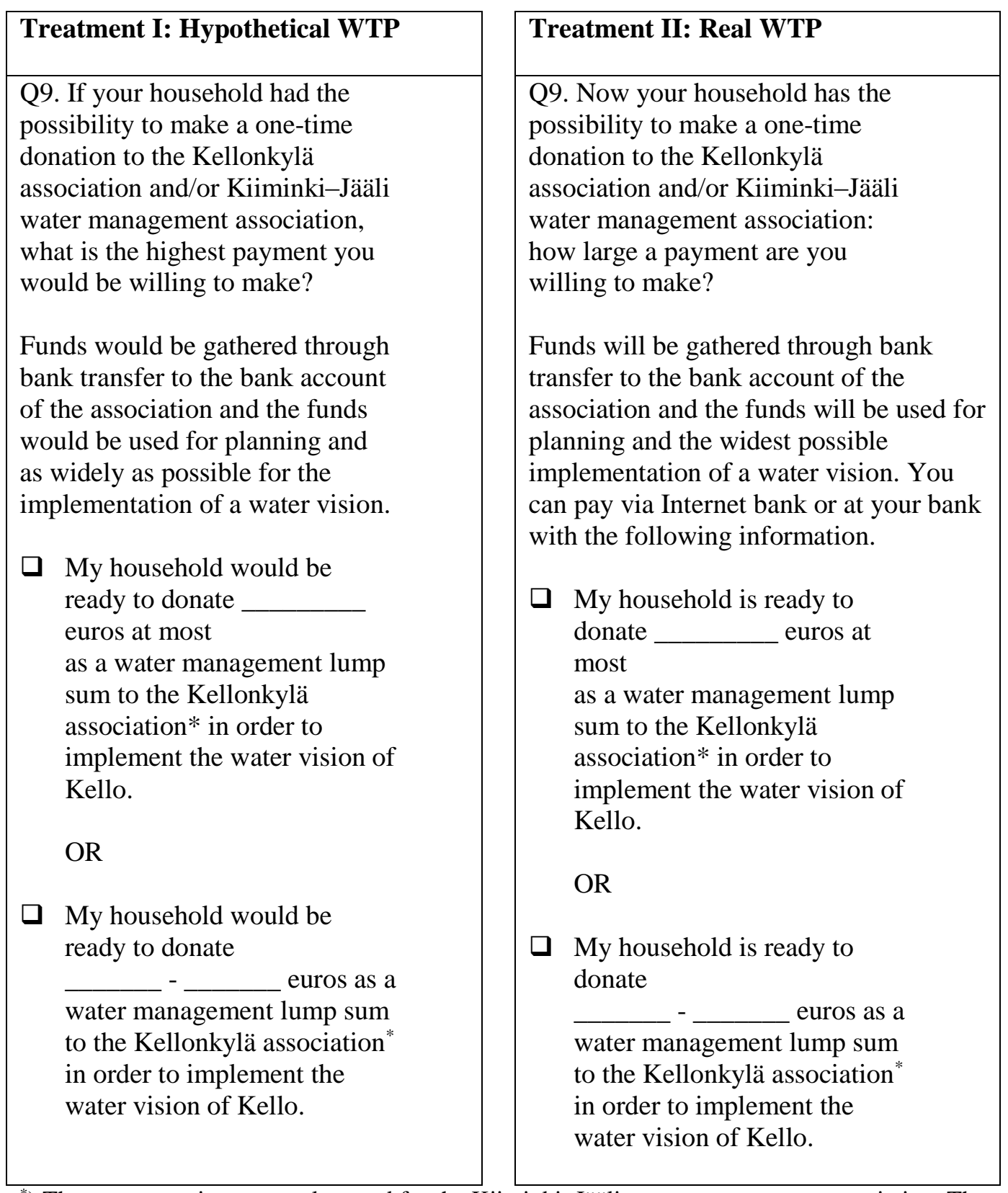

*) The same questions were also used for the Kiiminki-Jääli water management association. The respondent could choose to donate to one or both of the associations. 
785 Appendix B. Questionnaire to those who expressed willingness to pay, but who did not pay 786

787 1. I didn't pay because

788 (Choose the most suitable alternative and mark it with 1, and the second best alternative with 2):

789

790 [ ] I changed my mind about paying.

791 [ ] I couldn't afford to pay.

792 [ ] I forgot.

793 [ ] I wanted to consider the matter further.

794 [ ] I felt that I didn't support this project enough to pay for it.

795 [ ] I preferred voluntary work to donation.

796 [ ] Some other reason, what? 